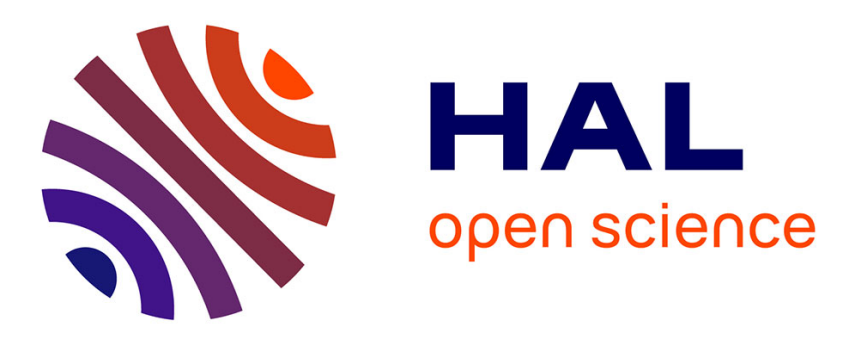

\title{
Hydrogenation of CeNi : hydride formation, structure and magnetic properties
}

Jean-Louis Bobet, Elie Grigorova, Bernard Chevalier, Maria Khrussanova, Pavel Peshev

\section{- To cite this version:}

Jean-Louis Bobet, Elie Grigorova, Bernard Chevalier, Maria Khrussanova, Pavel Peshev. Hydrogenation of CeNi: hydride formation, structure and magnetic properties. Intermetallics, 2006, 14 (2), pp.208-212. 10.1016/j.intermet.2005.05.006 . hal-00015800

\section{HAL Id: hal-00015800 https://hal.science/hal-00015800}

Submitted on 13 Dec 2005

HAL is a multi-disciplinary open access archive for the deposit and dissemination of scientific research documents, whether they are published or not. The documents may come from teaching and research institutions in France or abroad, or from public or private research centers.
L'archive ouverte pluridisciplinaire HAL, est destinée au dépôt et à la diffusion de documents scientifiques de niveau recherche, publiés ou non, émanant des établissements d'enseignement et de recherche français ou étrangers, des laboratoires publics ou privés. 


\title{
Hydrogenation of CeNi: hydride formation, structure and magnetic properties
}

\author{
J.-L. Bobet ${ }^{\text {b* }}$, E. Grigorova ${ }^{a}$, B. Chevalier ${ }^{b}$, M. Khrussanova ${ }^{a}$, P. Peshev ${ }^{\text {a }}$ \\ ${ }^{a}$ Institute of General and Inorganic Chemistry, Bulgarian Academy of Sciences, \\ Acad. G. Bonchev Str., Building 11, 1113 Sofia, Bulgaria \\ ${ }^{b}$ Institut de Chimie de la Matière Condensée de Bordeaux (ICMCB), \\ CNRS [UPR 9048], Université Bordeaux 1, 87 Avenue du Docteur A. Schweitzer, \\ 33608 Pessac Cedex, France
}

\begin{abstract}
The hydrogenation at different temperatures and hydrogen pressures of the binary intermetallic compound $\mathrm{CeNi}$ was studied. A hydride with the composition $\mathrm{CeNiH}_{2.9(1)}$ was obtained by hydriding the host alloy at $293 \mathrm{~K}$ and $\mathrm{P}_{\mathrm{H} 2}=1 \mathrm{MPa}$. With increasing temperature of hydriding a reaction of hydrogenolysis of $\mathrm{CeNi}$ occurred with formation of a stable two-phase product composed of $\mathrm{CeH}_{2.51}$ and $\mathrm{CeNi}_{5}$. The newly prepared hydride $\mathrm{CeNiH}_{2.9(1)}$ was found to be isostructural with $\mathrm{CeNi}$ (orthorhombic, CrB-type, S.G. Cmcm). On the basis of refinement of the XRD patterns of both the intermetallic compound and its hydride, the atomic positions of $\mathrm{Ce}$ and $\mathrm{Ni}$ and the interatomic distances were determined. The probable sites of hydrogen intersertion in the host structure were proposed. Moreover, a valence transition of cerium from intermediate valence $(\mathrm{CeNi})$ to the trivalent state $\left(\mathrm{CeNiH}_{2.9}\right)$ was evidenced by magnetization measurements.
\end{abstract}

Keywords: A. Rare-earth intermetallics; B. Crystal chemistry of intermetallics; B. Magnetic properties; F. Diffraction (electron, neutron and X-ray)

* Corresponding author. Tel.: +33 54000 2653; Fax: +33 540002761

E-mail address: bobet@icmcb-bordeaux.cnrs.fr 


\section{Introduction}

Hydrogen is an ideal non-polluting vector of energy for the future. Its use is closely associated with the methods of its storage. Among them the reversible bonding of hydrogen with some metals and alloys, forming hydrides, is of special interest. The 7.6 wt.\% absorption capacity of magnesium determines it as a very attractive material for hydrogen storage in the form of $\mathrm{MgH}_{2}$. However, the use of pure magnesium is prevented by its very poor hydrogen absorption and desorption kinetics. For that reason, a large number of investigations have been aimed at improving the kinetic characteristics of hydriding and dehydriding of magnesium by preparing composites on its basis with an absorption capacity close to that of pure Mg. A survey of the literature on this subject is given in some recent papers of the authors [1-3].

Nakhl et al. [4] were the first to study the hydrogen sorption properties of materials composed of $\mathrm{Mg}$ and an equiatomic intermetallic compound, $\mathrm{YNi}$, containing a rare earth and a VIII group transition metal. No reaction between the components of the composite was observed during its preparation by mechanical grinding but it was shown that the presence of $\mathrm{YNi}$ led to an improvement of magnesium hydriding kinetics even at relatively low temperatures. The X-ray diffraction patterns of the products obtained at $300^{\circ} \mathrm{C}$ after several hydriding-dehydriding cycles showed formation of $\mathrm{MgH}_{2}, \mathrm{Mg}_{2} \mathrm{NiH}_{4}, \mathrm{YH}_{2}$ and $\mathrm{YNiH}_{3}$.

In connection with the above results it was of interest to investigate the hydriding processes of magnesium-based composites containing $\mathrm{RNi}$ intermetallics of nickel with other rare earths. However, the authors are of the opinion that such investigations should be preceded by studies on the behaviour of the pure intermetallics during hydriding.

A survey of the crystal structures of $\mathrm{RE}_{\mathrm{x}} \mathrm{T}$ intermetallics where $\mathrm{RE}$ is a rare earth, $\mathrm{T}$ $=\mathrm{Co}, \mathrm{Ni}, \mathrm{Rh}, \mathrm{Pd}$ and $\mathrm{x} \geq 1$ is given in a review paper of Parthé and Moreau [5]. It is shown that nickel forms equiatomic RENi compounds with $\mathrm{Y}, \mathrm{La}, \mathrm{Ce}, \mathrm{Pr}, \mathrm{Nd}, \mathrm{Sm}, \mathrm{Gd}$ and $\mathrm{Tb}$. Of them only YNi crystallizes with monoclinic symmetry in the space group $P 2_{1} / c$ [6]. All the remaining compounds, excepting TbNi have a CrB-type (S.G. $\mathrm{Cmcm}$ ) orthorhombic structure. Depending on the way of preparation, TbNi crystallizes in space group Pnma or $P 2_{1} / m$ [7]. Irrespective of the available differences, all the above structures of equiatomic RENi compounds contain a common structural unit with nickel in the centre of trigonal prisms which are stacked differently to form each structure. Recently, Palumbo et al present a systematic study of the thermodynamics of Ce-Ni system [8].

The data available in the literature concerning the interaction of some RENi intermetallics with hydrogen are rather scarce and contradictory. Thus, there are communications on the preparation of LaNi hydrides with the composition $\mathrm{LaNiH}_{2.60}$ [9], $\mathrm{LaNiH}_{3.6}$ [10] and $\mathrm{LaNiH}_{3.85}$ [11]. More recently Verbetskii et al. [12] established hydriding at room temperature and a hydrogen pressure of $0.05-0.1 \mathrm{MPa}$ to lead to synthesis of $\mathrm{LaNiH}_{3.5}$ hydride with the same structure as that of the initial alloy. With increasing pressure up to $3 \mathrm{MPa}$, the hydride obtained in the range from room temperature to $673 \mathrm{~K}$ has the composition $\mathrm{LaNiH}_{2.8}$ and a structure analogous to that of $\mathrm{LaH}_{3}$. The same authors have found the intermetallic compound ErNi to begin 
interacting with hydrogen at room temperature only at $\mathrm{P}\left(\mathrm{H}_{2}\right) \geq 0.3-0.5 \mathrm{MPa}$. A hydride with the composition $\mathrm{ErNiH}_{3.4}$ and a structure differing from that of the initial compound is formed.

The hydrogenation of CeNi was also studied by Verbetskii et al. [12]. They noticed that under identical conditions hydrogenation of CeNi differed from that of LaNi in spite of the structural similarity of both intermetallics. Thus, CeNi hydride formation was found to start at room temperature and a hydrogen pressure of $0.005 \mathrm{MPa}$. Up to a pressure of $0.1 \mathrm{MPa}, \mathrm{CeNiH}_{3.7}$ was formed.

Increase of hydrogen pressure up to $3 \mathrm{MPa}$ leads to the formation of a hydride with the composition $\mathrm{CeNiH}_{2.9}$. If the temperature is enhanced up to $673 \mathrm{~K}$ at the same pressure, hydrogenolysis of $\mathrm{CeNi}$ proceeds according to the reaction

$$
5 \mathrm{CeNi}+6 \mathrm{H}_{2} \rightarrow 4 \mathrm{CeH}_{3}+\mathrm{CeNi}_{5}
$$

The present work represents a detailed study of the hydriding of $\mathrm{CeNi}$ and the resulting changes in structure and oxidation state of cerium.

\section{Experimental}

The starting intermetallic compound $\mathrm{CeNi}$ was synthesized by arc-melting under high-purity argon of a stoichiometric mixture of the elements with a $99.9 \%$ purity. To ensure homogeneity, the samples obtained were turned and remelted several times. After that they were annealed at $873 \mathrm{~K}$ for two weeks in evacuated silica tubes. Microprobe backscattering analyses showed the presence in the samples of $\mathrm{CeNi}_{2}$ as a parasitic phase. X-ray powder diffraction patterns needed for phase identification and structural analysis of the samples were obtained using a Philips PW 1050 diffractometer with a Bragg-Brentano geometry $\left(\mathrm{CuK}_{\alpha}\right.$ radiation). In determining the ternary hydride structure, the Rietveld method for refinement was applied [13], the diffraction patterns being analyzed by a whole pattern fitting procedure using the programme FULLPROF [14].

Hydrogen sorption properties were investigated with the use of an automatic Sievert type volumetric apparatus (HERA, Hydrogen Storage System, Québec, Canada) in the temperature range between room temperature and $723 \mathrm{~K}$. Hydriding experiments were carried out at $\mathrm{p}=1 \mathrm{MPa}$ while desorption proceeded at $\mathrm{p}=0.03 \mathrm{MPa}$. A detailed description of the volumetric method for hydrogen sorption measurements is given in [15].

Magnetic susceptibility measurements were carried out with both the CeNi alloy and its hydride using a Superconducting Quantum Interference Device (SQUID) magnetometer in the temperature range $1.8-300 \mathrm{~K}$ under an applied field of $4 \mathrm{~T}$.

\section{Results and discussion}

To study the hydrogenation process, the CeNi sample in small blocks was put in the hydriding reactor which was closed in a glove box under argon to avoid air 
contamination. After that the reactor was evacuated for about 15 min and hydrogen was introduced. The results of the first and second cycle of CeNi hydriding at room temperature and $\mathrm{p}=1 \mathrm{MPa}$ are shown in Fig. 1. The presence of an activation period during the first cycle is clearly visible. Obviously, this period is associated with the necessity to obtain cracks in the blocks, which would facilitate hydrogen diffusion. Subsequently CeNi begins to absorb hydrogen very quickly and an absorption capacity of $1.41(5)$ wt. $\% \mathrm{H}_{2}$ is achieved. This value corresponds to a composition $\mathrm{CeNiH}_{2.9(1)}$. This result is very far from that found by Verbetskii et al [12] who proposed the formula $\mathrm{CeNiH}_{3.7}$ for the product obtained under similar experimental conditions.

Practically no desorption of hydrogen from the sample hydrided at room temperature was observed and, as a result, a negligible absorption capacity during the second cycle was registered. The above pressures of absorption and desorption were used for performing hydriding/dehydriding cycles at 373, 473, 573, 623, 673 and 723 $\mathrm{K}$, respectively. In all cases there was no significant desorption. Even at the highest temperature about 0.1 wt.\% hydrogen were desorbed (Fig. 2). The X-ray pattern revealed the presence of a hydride of cerium, $\mathrm{CeH}_{2.51}$, and the intermetallic compound $\mathrm{CeNi}_{5}$, i.e. hydrogenolysis of $\mathrm{CeNi}$ had taken place according to the probable reaction

$$
5 \mathrm{CeNi}+5 \mathrm{H}_{2} \rightarrow 4 \mathrm{CeH}_{2.51}+\mathrm{CeNi}_{5}
$$

which differs from reaction (1) proposed by Verletskii et al [12].

The investigations showed proceeding of reaction (2) already at hydriding and dehydriding temperatures far below the maximum temperature applied in the present paper $(723 \mathrm{~K})$. This can be seen in the X-ray patterns shown in Fig. 3. The first pattern (Fig. 3a) corresponds to the $\mathrm{CeNiH}_{2.9(1)}$ hydride which is obtained after hydrogenation of the alloy at room temperature $(298 \mathrm{~K})$. The rise of the hydriding/dehydriding temperature up to $373 \mathrm{~K}$, however, leads to a product representing a not well crystallized (almost amorphous) mixture of $\mathrm{CeH}_{2.51}$ and $\mathrm{CeNi}_{5}$ (Fig. 3b). A similar hydrogen-induced amorphization (HIA) at relatively low temperatures accompanied by appearance of two new phases has been observed many times during hydriding of intermetallics of Laves phase type, $\mathrm{AB}_{2}$, where at least one of the metals forms a hydride [16-20]. Here one should note that the registered low temperature of hydrogenolysis of CeNi may not be quite correct. It may in reality be higher due to the strong exothermal effect of hydriding which can provoke appearance of local overheatings.

The X-ray patterns of the samples subjected to hydriding and dehydriding at higher temperatures show a much better crystallization of the product obtained after treatment at $573 \mathrm{~K}$ (Fig. 3c). At $723 \mathrm{~K}$ the characteristic peaks of $\mathrm{CeH}_{2.51}$ and $\mathrm{CeNi}_{5}$ are quite distinct in the X-ray pattern (Fig. 3d).

It is worth noting that no absorption was observed after hydriding $\mathrm{CeNi}$ even for a very long time at a low hydrogen pressure (e.g. $0.1 \mathrm{MPa}$ ). This contradicts the results of Verbetskii et al. [12] according to which the above pressure along with room temperature should lead to formation of a hydride with the composition $\mathrm{CeNiH}_{3.7}$, which was, however, not observed in the present study.

It was of interest to investigate the structure of the hydride $\mathrm{CeNiH}_{2.9(1)}$ obtained for the first time in the present work. For that purpose, the X-ray diffraction pattern of 
both the intermetallic compound and its hydride were scanned in the range from 5 to $120^{\circ}(2 \theta)$ in steps of $0.02^{\circ}$. It was established that $\mathrm{CeNiH}_{2.9(1)}$ crystallized in the same structure as $\mathrm{CeNi}$ (CrB-type, S.G. Cmcm). The good agreement between the calculated and the experimentally obtained pattern of the hydride is illustrated in Fig. 4 and the refined parameters are given in Table 1 . In the case of $\mathrm{CeNi}$, the refinement results are not as good as for the hydride due to a lower crystallinity of the sample but they show a sufficiently good agreement with published data.

The data in Table 1 show a considerable increase in parameters $b$ and $c$ of $\mathrm{CeNiH}_{2.9(1)}$ as compared to $\mathrm{CeNi}$ (12.77 and $10.66 \%$, respectively) whereas parameter $a$ displays a more moderate increase $(3.78 \%)$ as a result of hydrogen insertion. The unit cell volume increase is $29.5 \%$. This value is very high as compared to the $22 \%$ increase in the case of $\mathrm{LaNi}_{5}$ which absorbs more than twice as large quantity of hydrogen. The logical explanation of this result is the more compact crystal structure (type $\mathrm{CrB}$ ) of $\mathrm{CeNiH}_{2.9(1)}$. It is also worth noting that comparison between the values of $\Delta y / y(C e)$ and $\Delta y / y(N i)$ evidences that the cerium atom positions are less affected by hydrogenation than is the case of the nickel positions. Finally, in CeNi all Ce-Ni distances are equal to $2.97 \AA$ while in $\mathrm{CeNiH}_{2.9(1)}$ the hydrogen occupancy induces an anisotropic change, as a result of which each $\mathrm{Ni}$ atom is surrounded by 4 cerium atoms at a distance of $3.15 \AA$ (in the $a-c$ plane) and 2 cerium atoms at $3.37 \AA$ (in the $b$ direction). This change in the $\mathrm{Ni}$ environment proves that the hydrogen atoms are located in the $\left[\mathrm{Ce}_{3} \mathrm{Ni}\right]$ tetrahedra as was to be expected on the basis of the parameter changes. Moreover, for the isostructural $\mathrm{ZrNi}$ compound, the hydrogenation also induce a huge increase of the volume cell (i.e. the parameter $a, b$ and $c$ increase respectively of $7.9,5.5$ and $4.7 \%$ which lead to a increase of the volume cell of about $19.2 \%)$.

The structure under consideration can be described as an alternative stacking of $\mathrm{Ni}$ $\mathrm{Ce}$ and $\mathrm{Ce}-\mathrm{Ni}$ planes. The $\mathrm{Ce}$ and $\mathrm{Ni}$ displacement values given in Table 1 ( $\mathrm{y}=$ 0.12866 and 0.4237 in $\mathrm{CeNi}$ and $\mathrm{y}=0.13470$ and 0.40521 in $\mathrm{CeNiH}_{2.9(1)}$ for $\mathrm{Ce}$ and $\mathrm{Ni}$, respectively) led to an enhancement of the distance between two planes. This permits location of the hydrogen atoms in $\left[\mathrm{Ce}_{3} \mathrm{Ni}\right]$ tetrahedra between these planes. By analogy with the isostructural compound $\mathrm{ZrNi}$ it may be assumed that the $8 f$ sites in the structure are occupied by hydrogen, the hydrogen-metal distances being comparable to those reported for $\mathrm{ZrNiH}_{3}$ [21]. A similar occupation has also been reported for the equiatomic CeNiIn [22].

However, to achieve agreement with the formula $\mathrm{CeNiH}_{2.9(1)}$, the hydrogen should also occupy other sites. By analogy again with the hydride of $\mathrm{ZrNi}$, these are assumed to be sites $4 c$ in the trigonal bipyramide $\left[\mathrm{Ce}_{3} \mathrm{Ni}_{2}\right]$. Such occupation, which would lead to an increase of the three lattice parameters, was reported recently concerning some hydrides of the ternary cerium-based intermetallics [23, 24].

In most intermetallic compounds containing cerium, hydrogen absorption leads to a valence change of cerium atoms. This was the reason for carrying out magnetic susceptibility measurements on $\mathrm{CeNi}$ and $\mathrm{CeNiH}_{2.9(1)}$. The results are presented in Fig. 6. The binary compound $\mathrm{CeNi}$ exhibits a fluctuation valence behaviour (large minimum around $140 \mathrm{~K}$ in the curve $\chi_{\mathrm{m}}{ }^{-1}=\mathrm{f}(\mathrm{T})$ ), already reported by Clementiev et al. [25]. However, after hydrogenation with $\mathrm{CeNiH}_{2.9(1)}$ formation, this behaviour becomes the behaviour of a paramagnetic substance with a paramagnetic Curie 
temperature of $19 \mathrm{~K}$. The value obtained for the effective magnetic moment, $\mu_{\mathrm{eff}}=$ $2.46 \mu_{\mathrm{B}}$, is very close to that of $\mathrm{Ce}^{3+}\left(\mu_{\mathrm{eff}}=2.54 \mu_{\mathrm{B}}\right)$, which indicates that cerium in the hydride is in the trivalent state. Such a valence change has already been observed [26] with other Ce-based intermetallics. The increase of the unit celle volume induced by the hydrogenation leads to a decrease of the hydridization between $4 \mathrm{f}(\mathrm{Ce})$ states and conduction electron responsible of the intermediate valence behaviour of $\mathrm{CeNi}$. It is important to notice that in case of processing, even to a small extent, of $\mathrm{CeNiH}_{2.9(1)}$ dissociation to $\mathrm{CeH}_{2.51}$ and $\mathrm{CeNi}_{5}$, the magnetic measurement will at once reveal the presence of $\mathrm{CeNi}_{5}$ because this compound is a strongly magnetic one as compared to the ternary hydride. The foregoing permits the conclusion that the hydride obtained by $\mathrm{CeNi}$ hydriding at room temperature and $\mathrm{p}=1 \mathrm{MPa}$ contains no admixtures of dissociation products.

\section{Conclusion}

The results of the present investigation showed that hydrogenation of the intermetallic compound $\mathrm{CeNi}$ at room temperature and a hydrogen pressure above 0.1 $\mathrm{MPa}$, resulted in a hydride with the composition $\mathrm{CeNiH}_{2.9(1)}$. Hydriding at higher temperature led to hydrogenolysis of $\mathrm{CeNi}$ and formation of a two-phase mixture of $\mathrm{CeH}_{2.51}$ and $\mathrm{CeNi}_{5}$. All hydriding products were stable and practically no hydrogen desorption from them occurred up to $723 \mathrm{~K}$.

The $\mathrm{CeNiH}_{2.9(1)}$ hydride was isostructural with the binary intermetallic host compound (orthorhombic, S.G. Cmcm). Structural refinement showed that, as a result of hydride formation, all parameters increased, an increase of $29.5 \%$ of the unit cell volume being observed. It was established that the nickel atom positions were more strongly affected by hydrogenation than were cerium atoms. This resulted in a change of the nickel environment, the hydrogen atoms being located in the tetrahedral $\left[\mathrm{Ce}_{3} \mathrm{Ni}\right]$ $8 f$ sites and the trigonal bipyramidal $\left[\mathrm{Ce}_{3} \mathrm{Ni}_{2}\right] 4 c$ sites. Hydrogenation of $\mathrm{CeNi}$ with ternary hydride formation resulted in stabilization of the trivalent cerium state in the product.

\section{References}

[1] Khrussanova M., Bobet J.-L., Terzieva M., Chevalier B., Radev D., Peshev P., Darriet B., J Alloys Comp 2000; 307 : 283-289.

[2] Khrussanova M., Grigorova E., Mitov I., Radev D., Peshev P, J Alloys Comp $2001 ; 327: 230-234$.

[3] Bobet J.-L., Grigorova E., Khrussanova M., Khristov M., Radev D., Peshev P., J Alloys Comp 2002; $345: 280-285$.

[4] Nakhl M. , Bobet J.-L., Chevalier B., Darriet B., J Metastable Nanocryst. Mater 2000; $10: 637-642$.

[5] Parthé E., Moreau M., J Less-Common Met 1977; 53 : 1-24.

[6] Smith J.F., Hansen D.A., Acta Crystallogr. 1965; 18 : 60-62.

[7] Lemaire R. , Paccard D., TbNi, J. Less-Common Met. 1970; 21 : 403-413. 
[8] Palumbo M., Borzone G., Delsante S., Parodi N., Cacciamani G., Ferro R., Battezzati L. and Baricco M. , Intermetallics 2004; 12 : 1367-1372

[9] Maeland A.J., Andersen A.F., Videm K. , J Less-Common Met, 1976; 45 : 347-350.

[10] Oesterreicher H., Clinton J., Bittner H., Mater Res Bull, 1976; 11 : 1241-1247.

[11] Bush G. , Schlapbach L. , von Waldkirch Th., J Less-Common Met, 1978, 60 : 8389.

[12] Verbetskii N.N., Kayumov R.R., Semenenko K.N., Izv. Akad. Nauk SSSR, Metally 1991; 6:179-183. In Russian.

[13] Rietveld H.M., J Appl Crystallogr 1969; 2 : 65-71.

[14] Rodriguez-Carvajal J. , Physica B 192 ;1993 : 55-69.

[15] Tanguy B., Soubeyroux J.-L., Pezat M., Portier J., Hagenmuller P.,Mater Res Bull 1976; $11: 1441-1448$.

[16] Aoki K., Yamamoto T., Masumoto T., Scr Metall 1987; 21 : 27-31.

[17] Aoki K., Yanagitani A., Li X.G., Masumoto T., Mater. Sci. Eng. 1988; 97 : 35-38.

[18] Aoki K., Li X.-G., Aijara T., Masumoto T., Mater. Sci. Eng. A 1991; 133 : 316320.

[19] Aoki K., Masumoto T., J Alloys Comp 1995; 231 : 20-28.

[20] Dilixiati M., Kanda K., Ishikawa K., Aoki K., J Alloys Comp 2002; 337 : 128-135.

[21] Peterson S.W., Sadana V.N., Korst W.L., J Phys (Paris) 1964 ; 25 : 451-453.

[22] Matar S.F., Chevalier B., Eyert V., Etourneau J., Solid State Sciences 2003; 5 : 1385-1393.

[23] Vajeeston P., Ravindran P., Vidya R., Kjekshus A., Fjellvåg H., Yartys V.A., Phys Rev B, Cond. Matter Mater. Phys 2003 ; 67 : 014101-014112.

[24] Chevalier B., Pasturel M., Bobet J.-L., Decourt R., Etourneau J., Isnard O.,

Sanchez Marcos J., Rodriguez Fernandez J., J Alloys Comp 2004; 383 : 4-9.

[25] Clementyev E.S., Mignot J.-M., Alekseev P.A., Lazukov V.N., Nefeodova E.V.,

Sadikov I.P., Braden M., Kahn R., Lapert G., Phys. Rev. B, Cond. Matter Mater. Phys. 2000; $61:$ : 6189-6195.

[26] Javorsky P, Chernyavsky A, Sechvsky V, Physica B: Cond. Matter 2000; 281-282 : 71-72.

\section{Figure captions}

Fig. 1 The first (I) and second (II) cycle of hydriding of $\mathrm{CeNi}$ at room temperature and $\mathrm{P}=1 \mathrm{MPa}$

Fig. 2 Hydrogen absorption of $\mathrm{CeNi}$ and desorption of the hydride $\mathrm{CeNiH}_{2.9(1)}$ at $723 \mathrm{~K}$ and pressures of $1 \mathrm{MPa}$ and $0.03 \mathrm{MPa}$, respectively

Fig. 3 X-ray diffraction patterns of: (a) $\mathrm{CeNiH}_{2.9(1)}$; (b) a product hydrided at $\mathrm{T}=373 \mathrm{~K}$ and $\mathrm{p}=1 \mathrm{MPa}$ after dehydriding at the same temperature and $\mathrm{p}=0.03 \mathrm{MPa}$; (c) a product hydrided at $\mathrm{T}=673 \mathrm{~K}$ and $\mathrm{P}=1 \mathrm{MPa}$ after dehydriding at the same temperature and $\mathrm{n}=0.03 \mathrm{MPa}$;(d) a product hydrided at $\mathrm{T}=723 \mathrm{~K}$ and $\mathrm{p}=1 \mathrm{MPa}$ after dehydriding at the same temperature and $\mathrm{p}=0.03 \mathrm{MPa}$ 
Fig. 4 Experimental $(+)$ and calculated (solid line) X-ray diffraction patterns of $\mathrm{CeNiH}_{2.9(1)}$ and difference between them (bottom line)

Fig. 5 Representation of both $\mathrm{CeNi}$ and $\mathrm{CeNi}_{2.9(1)}$ structures with highlight of the possible sites occupied by hydrogen. Stars represent the $\mathrm{H}$ in $8 \mathrm{f}$ site as triangles represent the $\mathrm{H}$ in $4 \mathrm{c}$ site.

Fig. 6 Magnetic susceptibility vs. temperature relationships for $\mathrm{CeNi}$ and $\mathrm{CeNiH}_{2.9(1)}$ 
Table 1

Refined structural parameters of $\mathrm{CeNi}$ and $\mathrm{CeNiH}_{2.9(1)}$

\begin{tabular}{|c|c|c|c|c|c|c|c|c|c|}
\hline Compound & $a$ & $b$ & C & $V\left(\AA^{3}\right)$ & Atom & $\mathrm{x}$ & $\mathrm{y}$ & $\mathrm{z}$ & $B\left(\mathrm{~nm}^{2}\right)$ \\
\hline $\mathrm{CeNi}$ & $3.794(5)$ & $10.546(6)$ & $4.367(4)$ & 174.79 & $\begin{array}{l}\mathrm{Ce} \\
\mathrm{Ni}\end{array}$ & $\begin{array}{l}0 \\
0\end{array}$ & $\begin{array}{c}0.13866 \\
0.42370\end{array}$ & $\begin{array}{l}1 / 4 \\
1 / 4\end{array}$ & $\begin{array}{c}0.03213 \\
0.98007\end{array}$ \\
\hline
\end{tabular}

$\begin{array}{llllllllll}\mathrm{CeNiH}_{2.9(1)} & 3.938(4) & 11.893(7) & 4.832(4) & 226.39 & \mathrm{Ce} & 0 & 0.13470 & 1 / 4 & -.83631\end{array}$ $\begin{array}{lllll}\mathrm{Ni} & 0 & 0.40521 & 1 / 4 & 1.01424\end{array}$

$\Delta a / a=3.78 \% ; \quad \Delta b / b=12.77 \% ; \quad \Delta c / c=10.66 \% ; \Delta y / y(C e)=2.8 \% ; \Delta y / y(N i)=4.36$ $\%$

For CeNi: $R_{\mathrm{Bragg}}=10.95 \% ; R_{\mathrm{wp}}=32.9 \% ; R_{\mathrm{f}}=6.63 \%$

For $\mathrm{CeNiH}_{2.9(1)}: R_{\mathrm{Bragg}}=6.55 \% ; R_{\mathrm{wp}}=17.6 \% ; R_{\underline{\mathrm{f}}}=3.1 \%$ 


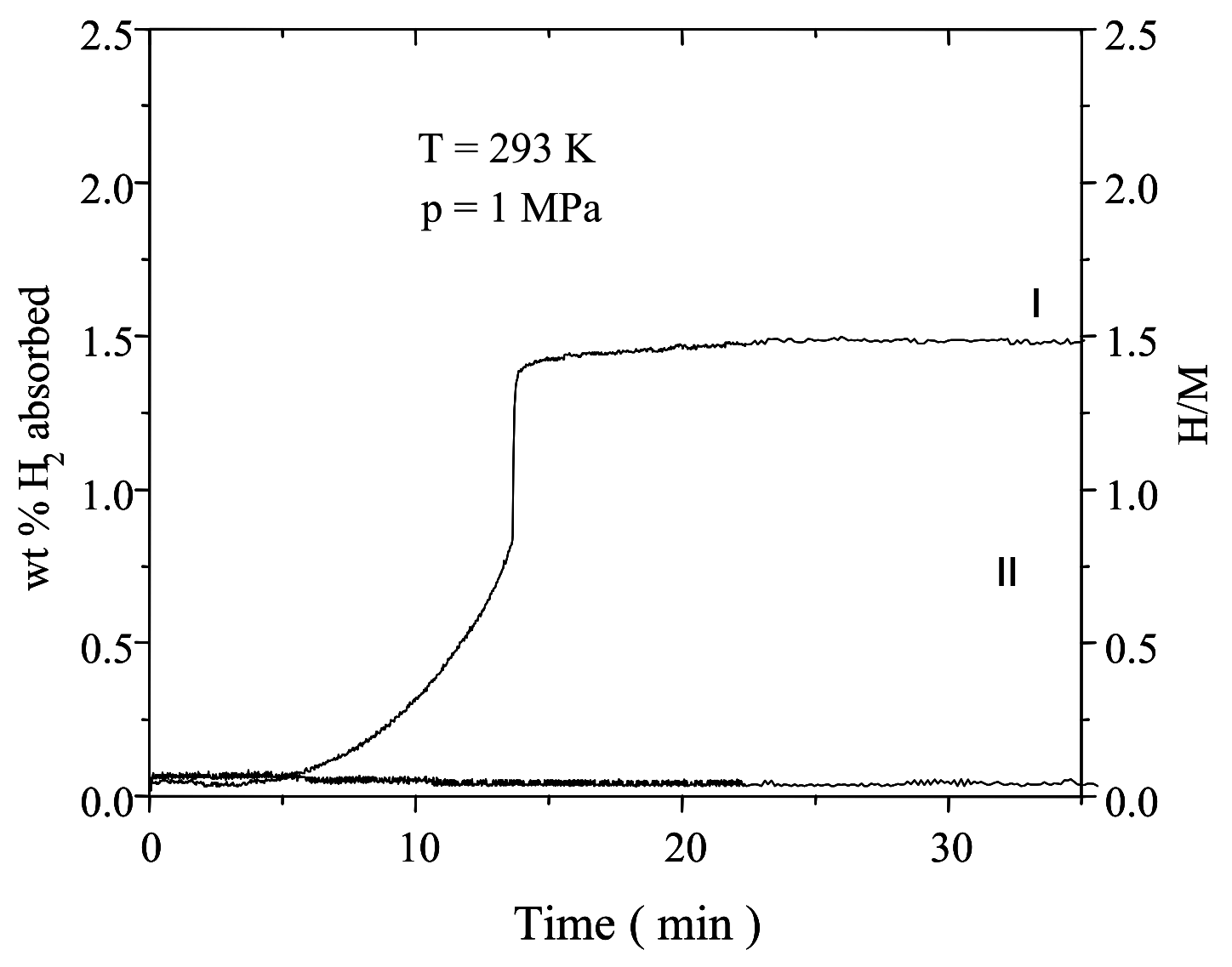

Bobet et al.

FIG. 1 




Bobet et al.

FIG. 2 


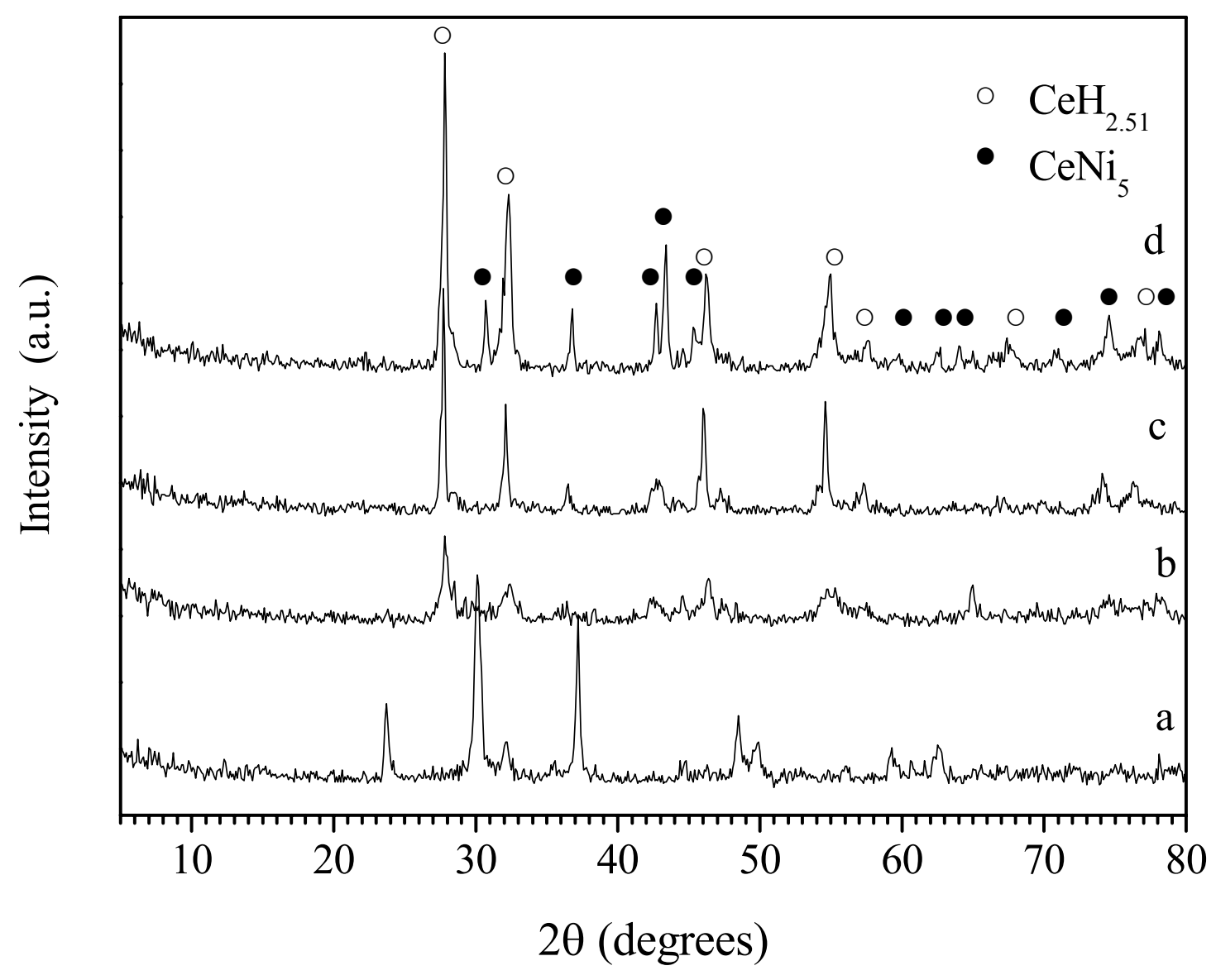

Bobet et al.

FIG. 3 




Bobet et al. FIG. 4 


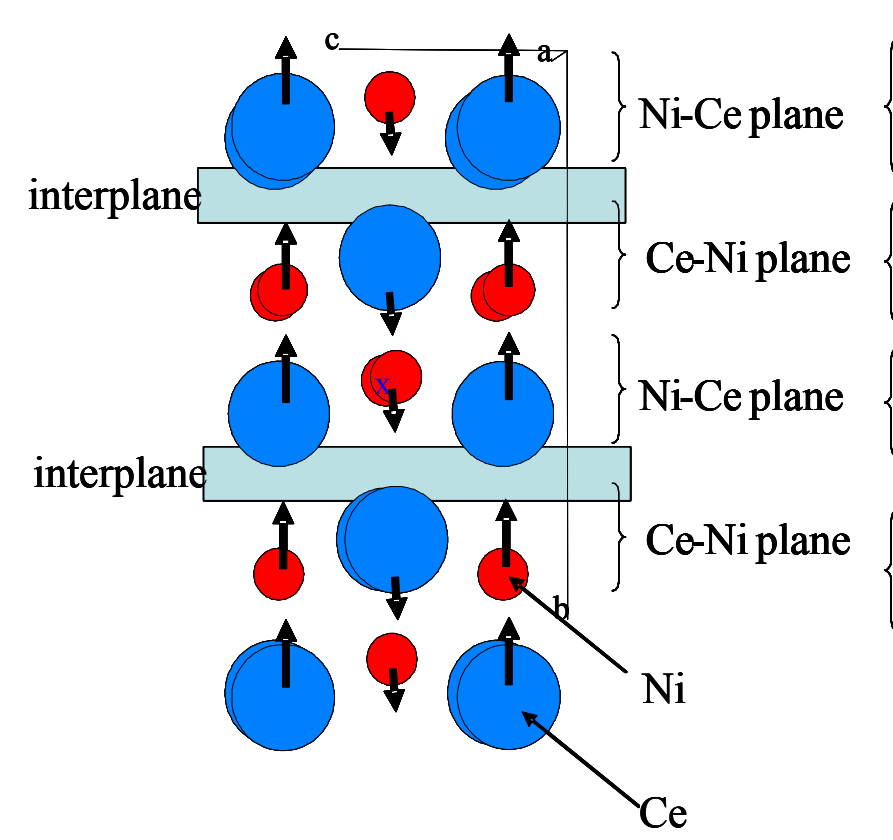

CeNi

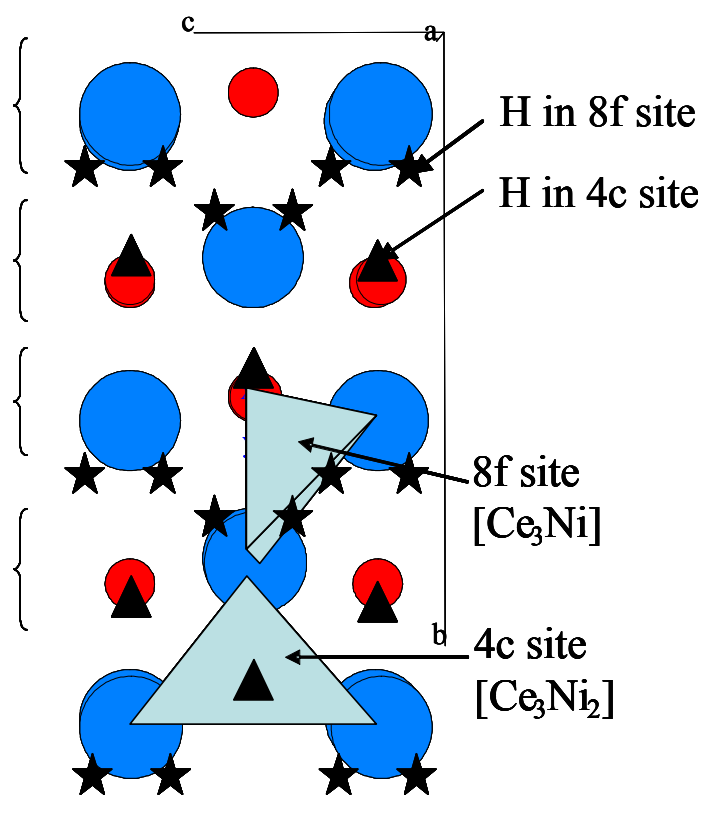

$\mathrm{CeNiH}_{2.9}$

Bobet et al.

FIG. 5 


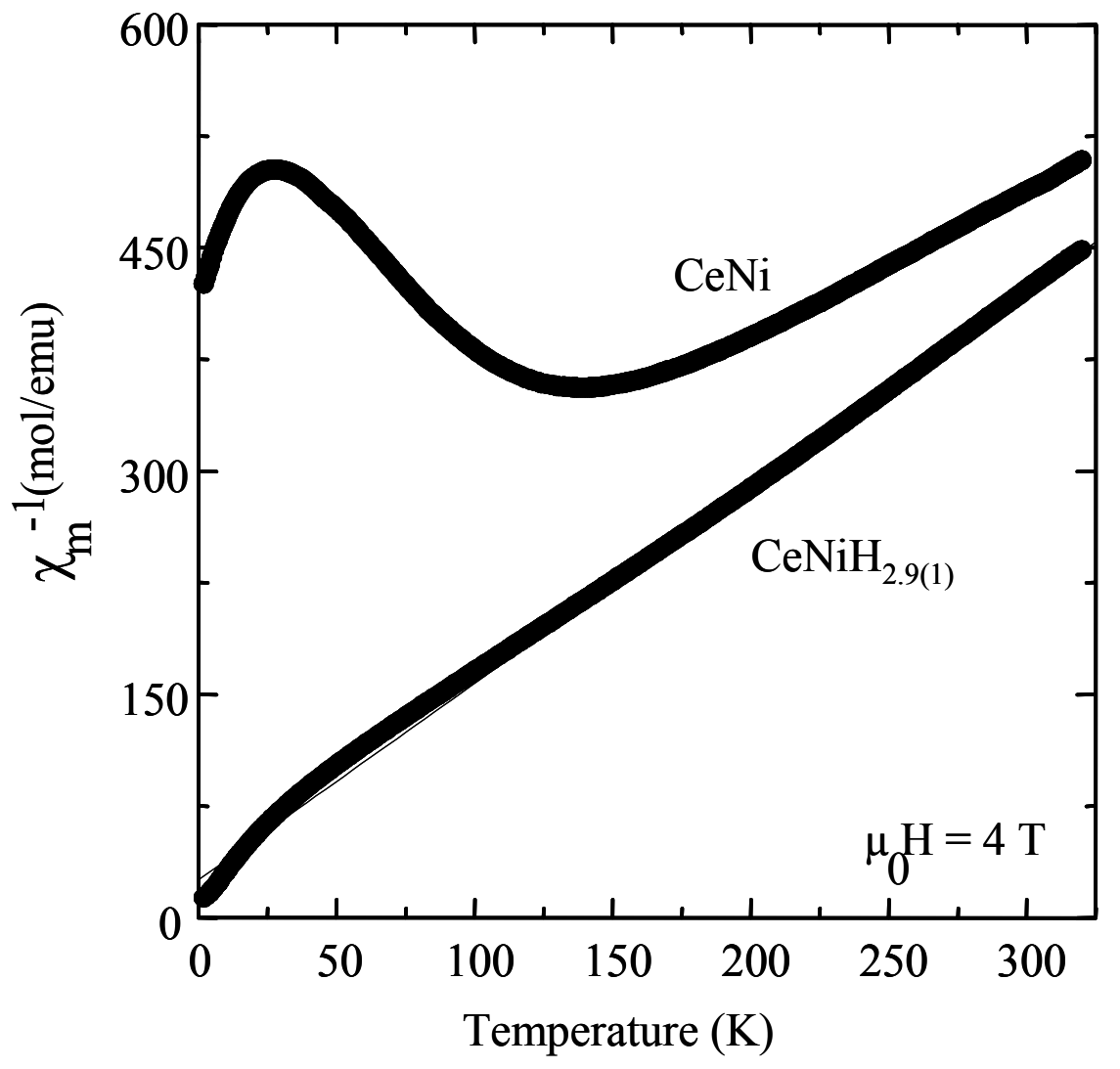

Bobet et al.

Fig.6 